\title{
MOBILIDADES COTIDIANAS DAS CRIANÇAS: COMBINANDO ETNOGRAFIA, GPS E TECNOLOGIAS DE TELEFONE MÓVEL EM PESQUISA*
}

\author{
Pia Haudrup Christensen ** \\ Miguel Romero MikKelsen ${ }^{* * *}$ \\ Thomas Alexander Sick Nielsen ${ }^{* * * *}$ \\ HENRIK HARDER ${ }^{* * * *}$
}

\begin{abstract}
RESUMO: Este artigo discute o desenvolvimento de uma abordagem com métodos mistos para o estudo da mobilidade diária das crianças. O estudo aqui apresentado combinou pesquisa etnográfica com a tecnologia de GPS (Global Positioning System) e um questionário interativo que as crianças completaram via telefone celular. Esta metodologia permitiu produzir uma compreensão mais ampla dos movimentos cotidianos das crianças por meio de um rico conjunto de dados, documentando as experiências subjetivas das crianças, as observaçôes sistemáticas, o mapeamento e levantamento de dados. Conclui-se que o sucesso de uma pesquisa usando métodos mistos requer uma estreita cooperação através do diálogo interdisciplinar e engajamento mútuo e coordenação de atividades e perspectivas.
\end{abstract}

Palavras-chave: Cidade. Infância. Mobilidade.

\section{CHILDREN'S EVERYDAY MOBILITIES: COMBINING ETHNOGRAPHY, GPS AND MOBILE PHONE TECHNOLOGIES IN RESEARCH}

ABSTRACT: This article discusses the development of a mixed methods approach to the study of children's everyday mobility. The study presented here combined ethnographic fieldwork with GPS (Global Positioning System) technology and an interactive questionnaire that the children completed via mobile phone. This methodology permitted the researchers to generate a fuller understanding of

\footnotetext{
* Uma versão ampliada do artigo foi publicada em: CHRISTENSEN, P. et al. Children, Mobility, and Space: using GPS and mobile phone technologies. Ethnographic Research Journal of Mixed Methods Research, London, v. 5, n. 3, p. 227-246, 2011. A Tradução do presente artigo foi realizada por Karin Quast e a revisão de tradução por Fernanda Müller.

** University of Leeds, Faculty of Education, Social Sciences and Law, School of Education, Leeds, UK. E-mail de contato: p.christensen@leeds.ac.uk.

*** University of Southern Denmark, Research Unit General Practice, Copenhagen, Denmark.

**** Technical University of Denmark, Institut for Transport, DTU Transport, Denmark.

***** Aalborg University, Department of Architecture, Design and Media Technology, Denmark.
} 
children's everyday movements through the rich dataset documenting children's subjective experiences, systematic observations, mapping and survey data. We conclude that the success of mixed methods research requires close cooperation through interdisciplinary dialogue and mutual engagement in and coordination of activities and perspectives.

Keywords: City. Childhood. Mobility.

\section{MOBILITÉ QUOTIDIENNE DES ENFANTS: L' ETHNOGRAPHIE, LE GPS ET LES TECHNOLOGIES DE TÉLÉPHONIE MOBILE EN RECHERCHE}

RÉSUMÉ: Cet article aborde l'élaboration d'une approche de méthodes mixtes pour l'étude de la mobilité quotidienne des enfants. L'étude présentée ici associe le terrain ethnographique avec la technologie du GPS (Global Positioning System) et un questionnaire interactif que les enfants ont rempli via téléphone portable. Cette méthodologie a permis de produire une compréhension plus complète des mouvements de la vie quotidienne des enfants à travers un riche ensemble de données qui a documenté les expériences subjectives des enfants, des observations systématiques, de la cartographie et des données de survey. On a conclu que le succès de la recherche sur les méthodes mixtes nécessite d'une coopération étroite entre le dialogue interdisciplinaire et l'engagement mutuel et la coordination des activités et les perspectives.

Mots-clés: Ville. Enfance. Mobilité.

\section{Introdução}

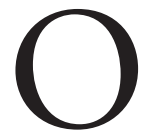

estudo aqui apresentado buscou compreender as características empíricas dos padróes de mobilidade diários das crianças no âmbito de seus contextos sociais, materiais e culturais. A noção de "mobilidade cotidiana" se refere a todo o espectro de movimentação corporal no qual as crianças se engajam durante suas atividades diárias (WHO, 1998), desde as atividades estacionárias realizadas enquanto estão paradas às atividades físicas mais vigorosas realizadas em um determinado local ou entre locais. Inclui-se também a noção de mobilidade cotidiana, definida como:

[...] toda saída de casa realizada em caráter temporário. Isso inclui viagens frequentes e regulares tais como o deslocamento para a escola ou o trabalho; saídas menos regulares, mas ainda assim frequentes, para visitar amigos ou parentes, para ir às compras, para praticar esportes e para outras atividades de lazer, incluindo a recreação infantil; e viagens realizadas somente uma ou duas vezes por ano, como as férias e visitas a parentes distantes. (POOLEY et al., 2005, p. 5) ${ }^{1}$ 
Durante as duas últimas geraçóes, os padróes de mobilidade das crianças europeias e norte-americanas mudaram radicalmente. (HILLMAN et al., 1990; KARSTEN, 2005; KEIM, 2005; O’BRIEN et al., 2000) Comparadas com a(s) infância(s) de seus avós, as crianças contemporâneas dos continentes europeu e norte-americano estão sujeitas a restriçóes marcadamente maiores em sua mobilidade cotidiana (POOLEY et al., 2005, p. 139-157), nomeadamente devido ao aumento na institucionalização da infância. (JAMES et al., 1998; RASMUSSEN, SMIDT, 2003; SMITH, BARKER, 2000) Conforme observado por esses estudiosos, a experiência diária das crianças, tanto em casa como na escola, é caracterizada por uma rigorosa supervisão e regulação de suas atividades por parte dos adultos. Vários estudos sugerem que o aumento na regulação da mobilidade e das atividades recreativas externas das crianças é, em grande medida, produto da crescente conscientização, por parte dos pais e das próprias crianças, acerca dos riscos. (O’BRIEN et al., 2000; VALENTINE, 1997) Para proteger as crianças dos supostos perigos das ruas, os pais cada vez mais levam e buscam seus filhos de carro de/para atividades educacionais e de lazer. (BARKER, 2003, 2009; FOTEL, 2007; HILLMAN et al., 1990; O’BRIEN et al., 2000) Um estudo conduzido na Dinamarca há dez anos mostrou que o número de crianças que eram levadas à escola de carro dobrou entre 1993 e 2000, e que crianças com idade entre 11 e 15 anos triplicaram suas viagens de carro em todas as jornadas entre 1978 e 2000. (JENSEN, HUMMER, 2002 apud FOTEL, THOMSEN, 2004, p. 538) Pesquisas sugerem que os ambientes urbanos e rurais nos dias atuais oferecem um milieu não amigável para a mobilidade independente e livre das crianças. $(\mathrm{CH}-$ RISTENSEN, O’BRIEN, 2003; MCKENDRICK, 2000)

\section{Um estudo acerca da mobilidade cotidiana das crianças usando métodos mistos}

Este artigo apresenta as percepções metodológicas oriundas de um estudo (que combinou vários métodos de pesquisa e coleta de dados) acerca da mobilidade cotidiana das crianças em uma área suburbana e uma área rural da Dinamarca. O estudo combinou métodos etnográficos com as novas tecnologias móveis e de rastreamento. O desenvolvimento desta metodologia para o estudo dos padrôes de mobilidade das crianças envolveu combinar uma abordagem direcionada pelo pesquisador com a pesquisa participativa, o que requereu o desenvolvimento de uma prática de pesquisa em conformidade com as rotinas e práticas diárias das crianças. Os pesquisadores convidaram ativamente as crianças participantes a refletir sobre o processo de pesquisa. Desta forma, suas visóes e observaçóes se tornaram centrais na forma como o estudo foi desenhado e levado a termo, incluindo suas reflexóes sobre o uso das tecnologias. 
O estudo foi desenvolvido com crianças que vivem em um subúrbio perto da capital, Copenhagen, e com crianças que vivem em uma área rural na parte nordeste da Dinamarca. A parte empírica do estudo foi desenvolvida ao longo de 12 meses, em 2005 e 2006, com o segundo autor deste artigo, que passou 3 dias por semana em campo. Quarenta crianças entre 10 e 13 anos e 29 famílias participaram do estudo. As crianças foram recrutadas por meio de duas escolas locais e um centro de atividades extraclasse após a aprovação do diretor e do conselho de administração. Posteriormente, no trabalho de campo, os pais das crianças participantes foram contatados e convidados a participar de uma entrevista. Nós estávamos interessados em estudar a movimentação das crianças na área local, incluindo na escola, no centro de atividades extraclasse e em casa.

\section{Etnografia}

O estudo etnográfico produziu dados aprofundados e detalhados sobre as experiências, práticas e rotinas das crianças no contexto de sua vida cotidiana. $\mathrm{O}$ conhecimento da mobilidade das crianças foi gerado por observaçóes, entrevistas, discussóes em grupo e conversas informais com as crianças, pais e professores. A observação participativa do cotidiano das crianças foi central para a pesquisa etnográfica, permitindo aos pesquisadores o conhecimento do tempo de permanência das crianças na escola durante as aulas, nos intervalos quando brincavam ao ar livre e após a escola quando passavam o tempo em casa e na sua comunidade local. $\mathrm{Na}$ maioria dos dias o pesquisador de campo juntava-se às crianças desde o início do dia letivo pela manhã e permanecia até à tardinha, quando as crianças retornavam para casa. As observaçóes de campo foram estruturadas e sistematicamente distribuídas entre as crianças participantes. A observação centrada por 30-60 minutos por semana durante um período de 6 meses, incluindo entrevistas, foi realizada com cada criança de cada um dos dois locais de estudo. As observaçóes focalizaram a forma como as crianças usavam seus espaços internos e externos, suas relaçôes sociais e interações com amigos, familiares, pares e outros. Essas observaçôes eram sistematicamente registradas em um diário de campo. Contudo, observar a mobilidade diária das crianças fora da escola e após o período escolar era, como mostraremos adiante, difícil, porque a movimentação era geograficamente dispersa e geralmente difícil de localizar.

As crianças também foram convidadas a levar o pesquisador de campo em uma visita guiada por sua comunidade local e a falar sobre as atividades e relacionamentos importantes para o seu uso diário da comunidade. Foram realizadas 16 entrevistas durante as visitas guiadas. Essas entrevistas guiadas, que duravam cerca de 60-90 minutos, deram ao pesquisador a oportunidade de adquirir experiência em primeira mão acerca dos locais favoritos das crianças e de seus 
percursos e rotinas diárias, bem como de observar as crianças no seu milieu natural. (CHRISTENSEN, 2003) As crianças decidiam o percurso e se a visita com o pesquisador deveria ser conduzida só por eles ou em companhia de um amigo ou membro da família. As conversas não tinham um formato pré-planejado, mas permitiam que o diálogo entre a criança e o pesquisador emergisse e se desenvolvesse conforme a visita se desenrolava, provocadas pelas pessoas que encontravam ou lugares que visitavam ao longo do percurso. Este método parte dos mapas mentais (emocionais e cognitivos) que as pessoas fazem dos lugares que conhecem e dos locais em que vivem: a casa, o bairro e a cidade. O "método de loci", como também é chamado, se refere à forma como os contextos espaciais e relacionais se entretecem na memória. (YATES, 1966)

\section{Tabela 1}

Número de crianças participantes nas diferentes partes do estudo

\begin{tabular}{|l|c|c|}
\cline { 2 - 3 } \multicolumn{1}{c|}{} & Meninos & Meninas \\
\hline Número Total de Participantes & 20 & 20 \\
Entrevista com grupos de pares & 6 & 6 \\
Entrevista durante a visita guiada & 9 & 7 \\
Entrevista com os pars & 17 & 12 \\
Rastreamento por GPS & 17 & 15 \\
Questionário por telefone celular & 5 & 7 \\
\hline
\end{tabular}

A entrevista durante a visita guiada forneceu uma percepção especial com relação à experiência das crianças acerca do lugar que ultrapassa o conhecimento que pode ser verbalizado em entrevistas tradicionais. O método de visita guiada foi crucial para obtermos uma compreensão profunda da movimentação das crianças e de suas jornadas fora de casa e da escola em sua comunidade local. Do mesmo modo que a escola e o centro de atividades extraclasse, o lar também constitui um importante local na vida cotidiana das crianças e atua como um ponto de partida e de chegada para sua mobilidade. (CHRISTENSEN, O'BRIEN, 2003; RASMUSSEN, 2004) Por esta razão, bem como pelo motivo das famílias constituírem uma parte importante em moldar o ambiente social das crianças, achamos importante colher dados contextuais sobre o lar e a vida familiar das crianças. Durante uma visita à família, os pais eram entrevistados sobre suas atitudes em relação à mobilidade independente das crianças e sobre suas práticas de criação referentes às atividades de lazer e a extensão de mobilidade na área local. 


\section{Mobilidade cotidiana das crianças: revisitando um dilema metodológico}

Observar a mobilidade externa diária das crianças apresentou a dificuldade etnográfica de explorar seus padróes de mobilidade em grande escala em tempo real. Diferentemente de seus pares mais velhos, as crianças nesta faixa etária (10-13 anos) não se reúnem ou "passam o tempo" nas ruas, parques ou centros comerciais locais. Embora algumas das crianças que viviam no subúrbio, especialmente as meninas, tendessem a passar tardes inteiras no centro comercial local, a mobilidade cotidiana das crianças ocorria por meio de seus percursos entre suas casas, a escola, o centro de atividades extraclasse e as atividades de lazer.

Em campo, portanto, o etnógrafo está limitado ao fato físico de só poder estar em um lugar de cada vez. De especial desafio são os eventos momentâneos ou ocasionais: "Como - por exemplo - observar as interaçóes que ocorrem ocasionalmente, mas não necessariamente quando estamos por perto? Como participar de ou observar as práticas que se desenrolam aqui e ali envolvendo uma ou poucas pessoas?" (MALKKI, 1997 apud AMIT, 2000, p.15) ${ }^{2}$

$\mathrm{Na}$ maior parte do tempo as crianças estavam em movimento, seja em espaços fechados ou externos, em suas casas ou na escola. Enquanto algumas de suas atividades físicas eram rotineiramente organizadas e orquestradas no tempo e no espaço pelos adultos na escola, no centro de atividades extraclasse ou clubes esportivos, outras atividades eram iniciadas de forma espontânea pelas crianças ou suas famílias. Isto significava que os requisitos metodológicos diferiam de acordo com o local. Na escola as crianças rotineiramente se agrupavam no mesmo espaço e tempo e suas atividades físicas (bem como outras atividades) eram programadas de forma a ocorrer em locais predeterminados e fixos. Qualquer desvio desses padróes seria geralmente, portanto, diretamente observável pelo pesquisador. $\mathrm{O}$ campo de ação era bem claro, na medida em que um pesquisador de campo com alguma experiência dos padróes temporais e espaciais da escola sabia onde e quando estar presente. Entretanto, ao final do dia letivo os padróes de mobilidade se alteravam. $\mathrm{Na}$ maioria dos dias as crianças saíam da escola gradual e paulatinamente se agrupavam em torno dos estacionamentos das bicicletas ou fora do portáo da escola para "bater papo". As crianças, então, se dispersavam em direçôes diferentes de sua comunidade local: para ir para casa, para o centro de atividades extraclasse, para aulas de música ou esportes ou para encontrar seus pais para irem às compras. Esse agrupamento diário fora da escola, às vezes, permitia que o pesquisador de campo tomasse providências junto a uma criança ou pequenos grupos de crianças para acompanhá-las de bicicleta ou a pé ao saírem da escola. Contudo, em outros dias, as crianças partiam rapidamente, deixando a sala, o pátio e o pesquisador para trás. 


\section{Rastreamento por GPS e a pesquisa por telefone celular}

Nós empregamos dois tipos de tecnologia: um receptor de Sistema de Posicionamento Global (GPS) e um telefone celular. O propósito do rastreamento por GPS era produzir um panorama visual e um conjunto de dados factual dos movimentos totais das crianças e a alocação geográfica do uso do tempo. Por meio do uso da tecnologia GPS nós buscamos compreender o panorama da mobilidade cotidiana das crianças em tempo e espaço real durante uma semana e, assim, 32 crianças das áreas urbana e rural carregaram o dispositivo GPS por sete dias a fim de incluir tanto a mobilidade durante a semana como no fim de semana. $\mathrm{O}$ período de sete dias representa um ponto de equilíbrio entre o desejo de capturar a variabilidade no padrão de mobilidade, incluindo atividades e comportamentos menos frequentes, e o fardo colocado nos participantes, bem como as demandas logísticas da pesquisa.

Para assegurar a qualidade das gravaçóes pediu-se às crianças que carregassem o GPS todo o tempo em que estivessem acordadas e o colocassem em algum lugar visível, como em seus pulsos ou no cinto, a fim de assegurar as melhores condiçóes para o posicionamento baseado em GPS. O equipamento não é capaz de gravar em ambientes fechados e roupas cobrindo o dispositivo podem prejudicar seu desempenho. Em princípio, os dados do GPS são gravados objetivamente porque a tecnologia que o produz não atribui sentido aos dados; contudo isso não significa, necessariamente, que o conjunto de dados produzirá uma representação objetiva da movimentação diária das crianças. Os dados do GPS foram gerados por meio de gravaçóes frequentes da posição geográfica das crianças e foram visualizados em fotografias aéreas. Essas fotografias produziram um retrato claro e coerente da mobilidade das crianças na paisagem no período de uma semana (ver Figura 1).

A Figura 1 apresenta os mapas básicos resultantes do rastreamento por GPS que estavam disponíveis aos pesquisadores para uso complementar à observação participante e entrevistas etnográficas na área rural de estudo. Cada mapa representa os rastros registrados por uma criança durante a semana em que participou da pesquisa com o GPS. Agrupamentos de 'pontos' indicam uma duração longa ou alta frequência de uso (especialmente a casa, escola e casas de amigos). $\mathrm{O}$ espaçamento de 'pontos' nos trajetos ou rotas depende da velocidade percorrida: viagens de carro deixavam apenas alguns pontos devido à alta velocidade, ao passo que formas mais lentas de locomoção, como de bicicleta ou a pé, deixam um rastro denso de pontos ao longo da rota. Os dados básicos dos 'pontos' também permitiram calcular e mapear o uso do tempo por localização. 


\section{Figura 1}

Mapas básicos resultantes do rastreamento
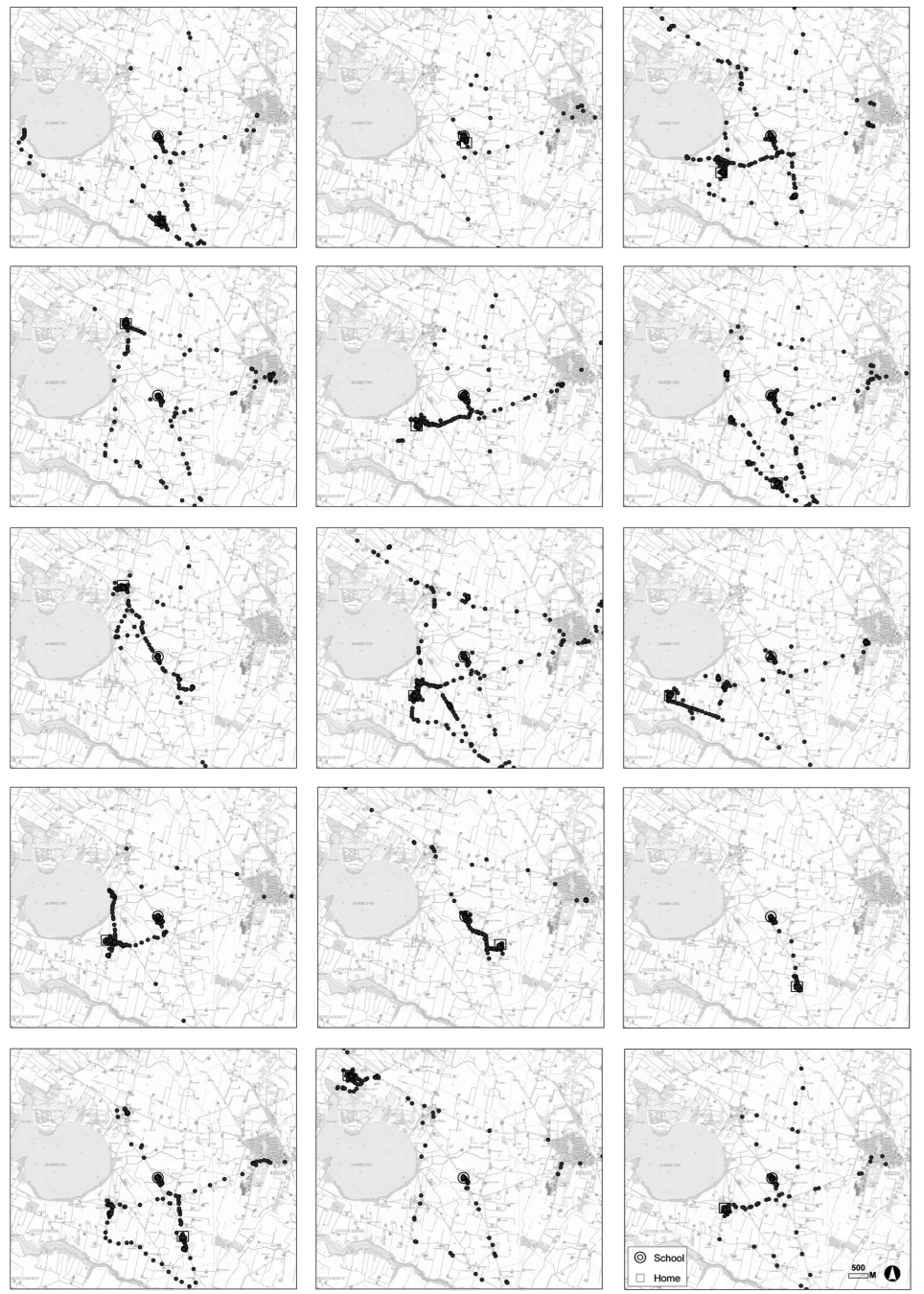

Os dados do GPS foram capazes de sustentar o trabalho de campo etnográfico e a análise interpretativa das interaçóes das crianças com os seus ambientes sociais e materiais. Nós produzimos dois tipos de mapa: o mapa itinerário que mostra o movimento contínuo dos respondentes e o mapa de permanência temporária usado para identificar o paradeiro dos respondentes e identificar os locais nos quais passaram mais/menos tempo. 
O telefone celular serviu como um meio para a pesquisa "itinerante autocontrolada" (self-controlled rolling). O objetivo da pesquisa era investigar quantitativamente e em tempo real as questóes chave sobre a movimentaçáo física das crianças e o uso das áreas vizinhas. Doze crianças que moravam no subúrbio participaram da pesquisa itinerante. Elas levaram os telefones celulares na mesma semana em que o GPS controlou os seus movimentos. No nosso estudo, o bipe anunciava a chegada de uma mensagem pedindo à criança que respondesse um pequeno questionário que consistia em cinco questôes. A mensagem de texto era enviada à criança cinco vezes ao dia. A pesquisa por telefone celular funcionou como um diário de jornada das atividades atuais das crianças, estimulando-as a relatarem sua mobilidade em tempo real - enquanto estavam em movimento. As questóes em ordem cronológica eram as seguintes: 1) O que você está fazendo? 2) Onde você está? 3) Você está em uma área fechada ou ao ar livre? 4) Como você chegou aî́? 5) Você foi sozinho ou acompanhado?

Devido às suas diferentes qualidades, as duas tecnologias foram utilizadas de forma complementar - o GPS gravava passivamente, ao passo que a pesquisa pelo celular requeria que as crianças informassem seus padróes de mobilidade de forma ativa. Após o experimento semanal nós conduzíamos duas entrevistas com as crianças. Na primeira entrevista as crianças foram convidadas a avaliar a adequação do desenho da pesquisa por celular e o uso prático da tecnologia GPS. A segunda foi baseada em uma fotografia aérea laminada da área local e de seus movimentos semanais individuais (conforme gravado pelo GPS). O mapa era usado para instigar um diálogo sobre a mobilidade diária das crianças e os locais que frequentavam durante a semana. A ideia era construir novas compreensóes acerca das jornadas das crianças quando o mapa lhes era apresentado. O objetivo desta entrevista era traçar uma conexão entre os padróes de mobilidade rotineiros e ocasionais das crianças na sua comunidade local (e além) e suas reflexóes, experiências e sentidos associados.

\section{Combinando etnografia e novas tecnologias: trabalhando com crianças}

Em pesquisas etnográficas com crianças, uma preocupação constante do pesquisador é se posicionar em campo de forma a trabalhar de forma bem sucedida tanto com as crianças como com os adultos. No presente estudo, tais preocupaçóes fizeram parte do estabelecimento de contato e a cuidadosa negociaçáo de acesso à escola e aos lares das crianças, seus grupos de amigos e sua movimentação dentro e fora da escola e no centro de atividades extraclasse. Nossa preocupação era estabelecer uma prática de pesquisa "em linha com as experiências, interesses, valores e rotinas diárias das crianças" ao longo de todo o processo da pesquisa. 
(CHRISTENSEN, 2004) Coerente com diretrizes éticas firmemente estabelecidas no que concerne a pesquisas com crianças, todos - crianças e pais - receberam informações acerca do estudo, seus métodos e objetivos através de folhetos, antes de sua participação no estudo. (ALDERSON, 1995; ALDERSON, MORROW, 2004) Foi pedido, também, o a assinatura de um termo de consentimento. Nós havíamos antecipado que as rotinas das crianças poderiam ser afetadas pelo evento não usual de portar um GPS. Contudo, em conversas com as crianças elas informaram que isso não afetou suas rotinas diárias. $\mathrm{Na}$ verdade, às vezes algumas crianças tiveram dificuldade em lembrar de levar o equipamento com elas.

Em nossa opinião, a elaboração do questionário foi essencial para o resultado bem sucedido da pesquisa. O questionário deveria ser de fácil entendimento para as crianças, permitir respostas imediatas e registrar dados precisos, pois as crianças poderiam receber o questionário quando estavam envolvidas em alguma atividade ou prestes a se movimentar de um local para outro. Os relatos das crianças subsequentemente apoiaram essa suposição, mas também confirmaram que nós havíamos sido apenas parcialmente bem sucedidos ao elaborar o questionário. Todas as crianças aprovaram a qualidade das questões, mas muitas contestaram, achando que a frequência das mensagens de texto causava interrupçóes e era muito intrusiva. A maioria das crianças concordou que elas só deveriam ter que responder ao questionário três vezes ao dia ao invés de cinco. Tal crítica também se refletiu na taxa de respostas, a qual, para algumas crianças, revelou-se bem baixa.

\section{Combinando etnografia e novas tecnologias: trabalhando com crianças}

A combinação de diferentes métodos de produção e análise de dados, neste estudo, foi possibilitada pela discussão contínua, coordenação e cooperação da equipe interdisciplinar de pesquisa ao longo de todo o processo. Nosso objetivo era atingir uma sinergia positiva ao invés de simplesmente trabalhar como equipes paralelas. A seguir discutiremos como efetuamos o conjunto de oportunidades metodológicas que Johnson et al. (2007, p.115) defendem como um desenho de métodos mistos eficaz pode oferecer. Eles argumentam que a combinação de múltiplos métodos acentua o princípio fundamental de validade (ou seja, qualidade) das descobertas da pesquisa por meio do que Denzin (1989) cunhou de "triangulação metodológica". Este princípio foi aprofundado de forma a encapsular a criação de um desenho de pesquisa onde as combinaçôes de métodos e abordagens são agrupadas de forma a partir de pontos fortes complementares e pontos fracos que não se sobreponham. (BREWER, HUNTER, 1989; JOHNSON, TURNER, 2003; ONWUEGBUZIE, JOHNSON, 2006) 


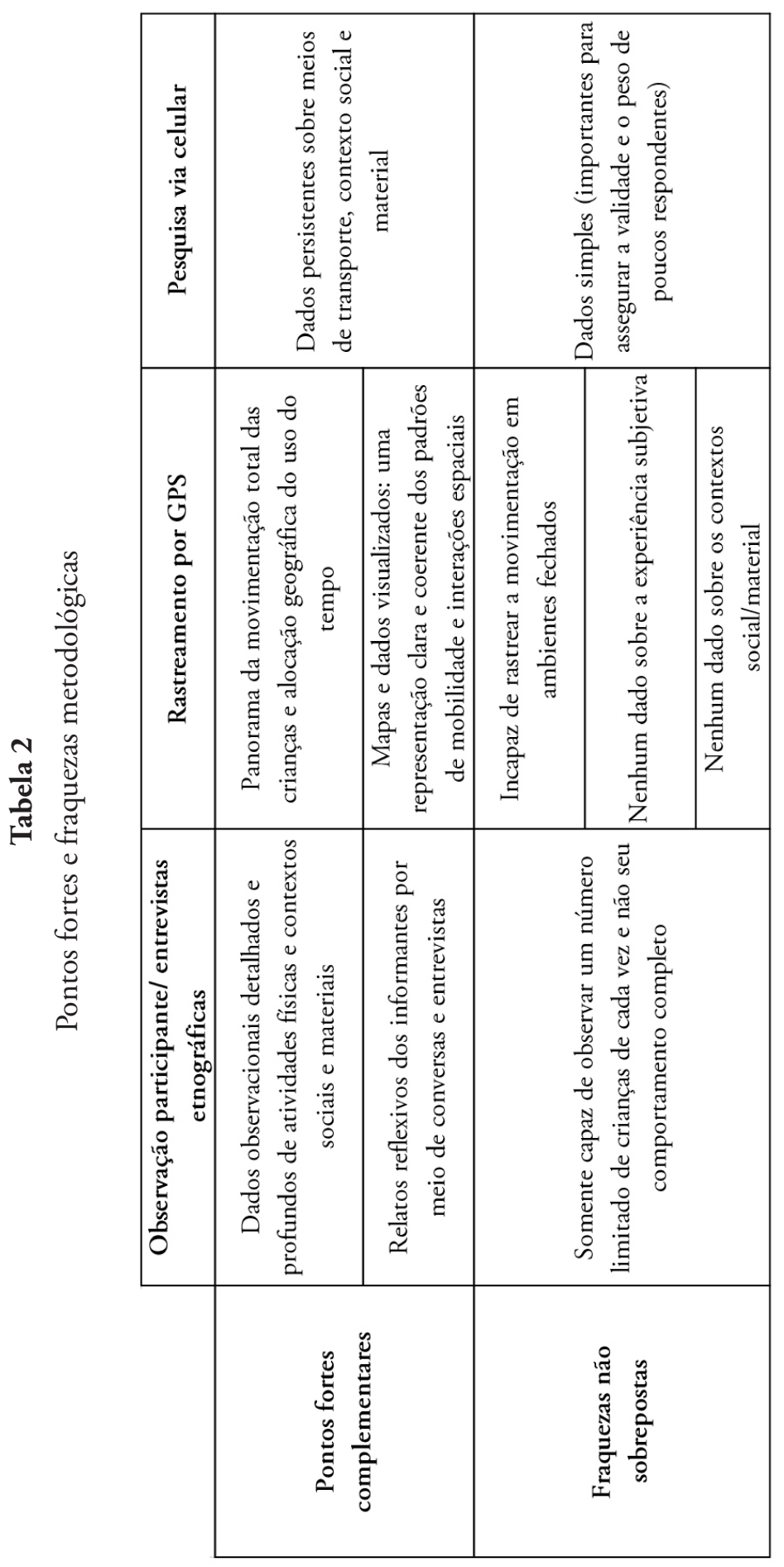


Conforme ilustrado na Tabela 2, o valor complementar dos diferentes métodos é alto e o desenho integrado aumentou a validade ao minimizar as fraquezas dos dados produzidos por meio de diferentes métodos. (ONWUEGBUZIE, JOHNSON, 2006)

A fim de maximizar a produção de dados e atingir uma sinergia produtiva entre os métodos qualitativos e quantitativos (GIBSON-DAVIS, DUNCAN, 2005), nós desenvolvemos o estudo de forma que seus diferentes componentes fossem integrados de várias formas. A pesquisa por celular fez uso de entrevistas e observaçóes etnográficas anteriores para formular as questóes e as categorias de "resposta fixa” no questionário. A observação etnográfica sugeriu que as crianças só raramente saíam desacompanhadas; na maior parte do tempo sua mobilidade ocorria em companhia de outras crianças e/ou adultos. Fazer tal pergunta na pesquisa por celular permitiu que o estudo coletasse dados mais exatos sobre o número de deslocamentos realizados em diferentes tipos de companhia. (MIKKELSEN; CHRISTENSEN, 2009) Tanto a programação como o momento de envio do questionário foram desenhados de forma que funcionassem de acordo com a rotina cotidiana das crianças. Quando as questóes funcionaram bem, elas forneceram um conjunto de dados consistente. Entretanto, na prática, a programação de envio das mensagens revelou-se não muito bem sucedida e há a necessidade de mais investigaçóes sobre como aumentar a taxa de respostas.

Nós também combinamos técnicas de forma que os diferentes métodos e conjuntos de dados se retroalimentassem. Por exemplo, o mapa aéreo das rotas das crianças, gerado pela tecnologia GPS, foi combinado com o uso da entrevista qualitativa baseada nas fotografias por meio de uma conversa sobre os padróes de mobilidade semanais. Cada mapa precisava então ser examinado para verificar a ocorrência de registros errôneos por parte do GPS. O conhecimento do pesquisador de campo acerca dos movimentos diários de cada criança participante e da área local tornou isso possível. Os dados contextuais e a interpretação, que somente os dados etnográficos podem fornecer são, portanto, muito importantes para assegurar a qualidade dos mapas gerados pelo GPS.

Da mesma forma que a observação participante, as novas tecnologias são capazes de gerar dados sobre as práticas, atividades e relaçóes sociais em tempo real. Contudo, ao passo que o etnógrafo é capaz de gerar dados detalhados e profundos sobre as práticas, experiências e significados, os dados produzidos via GPS e telefone celular são mais simples, no sentido de que tais dados quantitativos são projetados de forma a enfocar a posição geográfica de seu portador e os dados contextuais específicos que o questionário podia produzir. A combinação do GPS com o telefone celular permitiu, portanto, o estudo de um número maior de crianças simultaneamente. Por exemplo, se o pesquisador queria saber para onde uma criança se dirigia em uma segunda-feira à tarde depois de sair da escola, ou onde as crianças se agrupavam em uma manhã de domingo, o GPS podia revelar 
tal informação. O método GPS por si só, no entanto, não conseguia informar precisamente como as crianças se movimentavam: se elas iam a pé, de bicicleta, de patins ou se sua movimentaçáo ocorria no banco traseiro do carro de seus pais. Também não era capaz de fornecer o contexto social da movimentação e, consequentemente, a distribuição das crianças se movimentando sozinhas ou acompanhadas. Também seria impossível para o mapa, por si só, saber o motivo das crianças escolherem um percurso em particular e náo outro - ou, na verdade, porque elas faziam uma determinada parada no percurso. Os dados do questionário por celular foram capazes de fornecer um panorama mais completo.

Gerados por intermédio de instantâneos repetidos das práticas de mobilidade diárias das crianças, o questionário produziu conhecimento desses importantes elementos contextuais. Isso foi então enriquecido pelos detalhes e percepçóes obtidos da etnografia. Além disso, a etnografia e o celular foram capazes de produzir dados sobre as atividades das crianças em ambientes fechados. O GPS não foi capaz de fazê-lo. Com o GPS e o questionário via celular nós contávamos com dois instrumentos que, devido a suas capacidades diferenciadas e complementares, atuaram de forma a produzir um panorama quantitativo do padrão de mobilidade das crianças. Métodos etnográficos tradicionais isolados não foram capazes de produzir tal percepção pelo simples fato de que o pesquisador de campo (que é considerada a mais importante ferramenta na pesquisa etnográfica) não podia observar todas as crianças o tempo todo e simultaneamente. A etnografia nos permitiu produzir dados aprofundados, não apenas sobre a mobilidade diária das crianças, mas também sobre suas experiências e sua compreensão no contexto de seu ambiente social e material. Acima de tudo, a combinação da etnografia com o GPS e a pesquisa por celular forneceu tal panorama e a compreensão detalhada dos significados dos padróes de mobilidade individuais e coletivos das crianças.

A descoberta geral da pesquisa foi de que a mobilidade das crianças é basicamente de natureza social e que a companhia é um aspecto central. (MIKKELSEN; CHRISTENSEN, 2009) Quando combinados, os dados enfatizaram a necessidade de levar em consideração a diversidade de movimentos das crianças. O GPS e a pesquisa pelo celular revelaram semelhanças e diferenças importantes entre os padrốes de mobilidade das crianças que vivem em vilas rurais e no subúrbio. Os dados do GPS documentaram os destinos e a extensão das movimentaçôes durante a semana e nos fins de semana. Os dados do telefone celular mostraram que enquanto a mobilidade das crianças na área rural envolvia, em grande parte, a família, bichinhos de estimação e animais, para as crianças da área suburbana esta envolvia principalmente outras crianças. Tanto na área rural como na suburbana a companhia provou ser importante para as crianças durante suas jornadas para escola e quando perambulavam pela vizinhança. Os dados etnográficos revelaram que as crianças preferiam a companhia de outros devido ao senso de companheirismo e segurança que fornecia, quando comparado a jornadas desacompanhadas. 
Da mesma forma, os pais tanto de crianças da área rural como da suburbana valorizavam o fato das crianças andarem acompanhadas. As observaçóes etnográficas mostraram que a mobilidade cotidiana das crianças suburbanas e de seus pais era bem distinta. Os pais de famílias suburbanas ambos trabalhavam em tempo integral e em seus relatos sua preocupação era de que as crianças desenvolvessem a habilidade de ir sozinhos à escola e às atividades de lazer. A vida familiar era caracterizada por pais e filhos envolvidos em atividades separadas durante a semana e atividades familiares em conjunto eram alocadas nos fins de semana. No subúrbio, a mobilidade conjunta de pais e filhos incluía ir às compras e visitas a familiares. A companhia de outras crianças era vista como uma maneira de garantir a segurança e a proteção da criança quando os pais não estavam presentes para os transportarem durante a semana. Em contrapartida, pais e filhos vivendo na área rural tendiam a se deslocar conjuntamente ao longo da semana, geralmente como parte de suas atividades de lazer. Isso substanciava e encorajava o valor da companhia na mobilidade familiar e fazia parte de uma rede de interdependência familiar. $\mathrm{Na}$ área rural, a prevalência de apenas um dos pais ter um emprego de tempo integral fora de casa permitia o caráter interconectado da mobilidade diária de filhos e pais. Os dados sobre os contextos das famílias, processos da vida cotidiana e os significados subjacentes aos padróes de mobilidade das crianças foram revelados por métodos etnográficos e demonstram que diferenças geográficas (como a comparação entre área rural/suburbana discutida anteriormente), culturas de coesão social dentro das famílias e os padróes de emprego dos pais são significativos para se compreender como a mobilidade das crianças é moldada.

No entanto, apesar das diferenças entre as famílias na área rural e urbana, a pesquisa por celular e a etnografia mostram que a companhia de outros perpassava a mobilidade das crianças. Essa característica social, juntamente com as variaçóes na mobilidade das crianças descrita anteriormente, indica a necessidade de reconsiderar a noção de "mobilidade independente" das crianças. A centralidade desse conceito nos debates e estudos sobre mobilidade infantil conduziu, argumentamos, a uma ênfase desproporcional na movimentação individual e autônoma das crianças. Esta ênfase não reflete como as próprias crianças neste estudo compreendem e avaliam sua movimentação. Os dados etnográficos mostraram que para as crianças, sair sozinhas não era sua prioridade. Para elas, as atividades físicas diárias eram mais apreciadas quando os deslocamentos, os jogos, brincadeiras e as saídas envolviam outras pessoas com quem podiam criar e compartilhar experiências e com as quais se sentiam confortáveis. Para as crianças não era tão importante se estavam acompanhadas de outras crianças, membros da família ou bichinhos de estimação (embora cada criança pudesse ter suas preferências pessoais).

Enquanto as descobertas acima contribuem para a literatura empírica sobre a mobilidade infantil ao combinar métodos quantitativos e qualitativos para revelar diferenças nos padróes e significados da mobilidade de diferentes crianças, 
seu significado mais amplo encontra-se no debate teórico atual sobre a noção de "mobilidade independente" nos estudos sobre a mobilidade infantil. Entretanto, o estudo aqui relatado deu lugar a uma discussão crítica mais ampla: a de que o conceito de mobilidade independente não está bem definido; de que coloca uma ênfase muito grande na presença/ausência de adultos, ao passo que simultaneamente desvaloriza a influência dos pais por meio de regras familiares e comunicação móvel; e de que o conceito de "mobilidade independente" é sustentado por uma posição de valor não questionada que coloca a independência como o foco da atenção, levando a um enfoque empírico no deslocamento individual e autonomia na movimentação. (MIKKELSEN; CHRISTENSEN, 2009) A importância do presente estudo para este debate possui três vertentes. Primeiramente, é aparente que para as crianças que fizeram parte do estudo o deslocamento por conta própria não é sua prioridade. Para elas, as atividades físicas diárias eram mais apreciadas quando as jornadas, brincadeiras, jogos e saídas envolviam outras pessoas com as quais elas podiam criar e compartilhar experiências e com quem elas se sentiam confortáveis. Em segundo lugar, as crianças se deslocavam com vários tipos de companhias - outras crianças, membros da família e animais de estimação. A situação era mais complexa do que a mera escolha entre o deslocamento com ou sem a companhia de um adulto. Em terceiro lugar, os padróes de movimentação mostrados pelo estudo e as formas nas quais eram moldados estáo relacionados a padróes mais amplos de interdependência nas relaçóes familiares ao invés de independência dos pais (ou adultos, falando mais genericamente). Tais percepçóes contribuirão para o debate em andamento sobre se a independência é a lente mais útil por meio da qual a mobilidade infantil pode ser vista ou se esta deve ser vista mediante as diferentes configuraçóes de interdependência.

\section{Conclusão}

No campo de estudos sociais de crianças tem sido frequente criar inovaçóes e novas combinaçóes de métodos qualitativos tais como entrevista, desenho, fotografia e mapeamento. No entanto, somente alguns pesquisadores mais recentemente combinaram métodos qualitativos e quantitativos no estudo da mobilidade. Embora as abordagens de métodos mistos possam não ser apropriadas para toda pergunta de pesquisa, o tempo, o conhecimento especializado requerido e os recursos necessários significam que elas têm sido frequentemente rejeitadas (ou nem mesmo consideradas). No estudo aqui apresentado, combinar a etnografia com métodos tecnológicos inovadores constituiu uma triangulação metodológica que aumentou a validade dos dados acerca da mobilidade infantil. Em particular, os pontos fortes de um método foram usados para compensar os pontos fracos de outro. O uso de novas tecnologias compensou algumas das dificuldades relacionadas ao estudo etnográfico dos padróes de mobilidade das crianças. Con- 
forme discutido acima, o uso prático e técnico das tecnologias móveis no presente estudo não ocorreu sem problemas. Entretanto, atuando em conjunto, a etnografia e as novas tecnologias funcionaram de forma bem sucedida produzindo um conjunto de dados com múltiplas camadas, o que torna possível desenvolver uma análise que pode ampliar e aprofundar nossa compreensão acerca da mobilidade cotidiana das crianças (ver, por exemplo, MIKKELSEN; CHRISTENSEN, 2009) por intermédio da utilização de uma abordagem holística em seu estudo.

\section{Notas}

1. [...] all travel from home undertaken on a temporary basis. This includes frequent and regular trips such as the journey to school or to work; less regular but still frequent trips to visit friends or relatives, to shop, for sport and for other leisure activities including children's play; and trips undertaken only once or twice a year such as holidays and visits to distant relatives. (POOLEY et al., 2005, p. 5)

2. How - for instance - do we observe interactions that happen sometimes but not necessarily when we are around? How do we participate in or observe practices that are enacted here and there by one or a few people?. (MALKKI, 1997 apud AMIT, 2000, p. 15).

\section{Referências}

ALDERSON, P. Listening to children: children, ethics and social research. Barkingside: Barnado's, 1995.

ALDERSON, P.; MORROW, V. Ethics, social research and consulting with children and young people. Barkingside: Barnardo's, 2004.

AMIT, V. Introduction. In: . (Ed.). Constructing the field. London: Routhledge, 2000. p. 1-18.

BARKER, J. Driven to distraction? Children's experiences of car travel. Mobilities, London, v. 4, n. 1, p. 59-76, Feb. 2009.

BARKER, J. Passengers or political actors? Children's participation in transport policy and the micro political geographies of the family. Space \& Polity, London, v. 7, n. 2, p. $135-151,2003$.

BREWER, J.; HUNTER, A. Multi-method research: A synthesis of styles. NewburyPark, CA: Sage, 1989.

CHRISTENSEN, P. Place, space and knowledge: Children in the village and the city. In: CHRISTENSEN, P.; O’BRIEN, M. (Eds.) Children in the city. London: Routledge Falmer, 2003. p. 13-28.

. Children's participation in ethnografic research: Issues of power and representation. Children \& Society, New Jersey, v. 18, n. 2, 165-176, 2004. 
DENZIN, N.K. The research act: a theoretical introduction to sociological methods. 3rd ed. Englewoods Clifs, New Jersey: Prentice Hall, 1989.

FOTEL, T. Mobilitet i børnehøjde: en mobilitetssociologisk analyse af praksis, velferd og ulighed $i$ borns hverdagsliv [Child-wise mobilities: an analysis of practice, welfare, and equalities in children's everyday lives from the perspective of the 'sociology of mobility']. $\mathrm{PhD}$ thesis no. 55/2007. Institut for Samfund og Globalisering. Roskilde Universitet, 2007.

GIBSON-DAVIS, C. M.; DUNCAN, G. Qualitative/quantitative synergies in a random-assigment program evaluation. In: WEISNER, T. S. (Ed.). Discovering successful pathways in children's development: mixed methods in the study of childhood and family life. Chicago: University of Chicago Press, 2005. p. 283-303.

HILLMAN, M.; ADAMS, J.; WHITELEGG, J. One false move. London: Policy Studies Institute, 1990.

JAMES, A., JENKS, C.; PROUT, A. Theorizing childhood. Cambridge: Polity Press, 1998.

JOHNSON, R. B.; ONWUEGBUZIE, A. J.; TURNER, L. Toward a definition of mixed methods research. Journal of Mixed Methods Research, London, v. 1, n. 2, p. 112-133, April 2007.

JOHNSON, R. B.; TURNER, L. Data collection Strategies in mixed methods research. In: TASHAKKORI, A; TEDDLIE, C. (Eds.). Handbook of mixed methods in social and behavioral research. Thousand Oaks, CA: Sage, 2003. p. 279-319

KARSTEN, L. It all used to be better? Different generations on continuity and change in urban children's daily use of space. Children's Geographies, New Jersey, v. 3, n. 3, p. 275-290, 2005.

KEIM, S.A. The national children's study of children's health and the environment: an overview. Children, Youth and Environments, Colorado, v. 15, n. 2, p. 240-256, 2005.

MCKENDRICK, J.H. The Geography of Children: An Annotated Geography. Childhood, Norway, v. 7, n. 3, p. 359-387, aug. 2000.

MIKKLESEN, M. R.; CHRISTENSEN, P. Is children's independent mobility really independent? A study of children's mobility combining ethnography and GPS/mobile phone technologies. Mobilities, London, 4, 37-38, 2009.

O'BRIEN, M.; JONES, D.; SLOAN, D. Children's independent spatial mobility in the urban public realm. Childhood, Norway, v. 7, n. 3, p. 257-277, aug. 2000.

ONWUEGBUZIE, A.J.; JOHNSON, R. B. The validity issue in Mixed Research. Journal of Research in the Schools, Houston, v. 13, n. 1, p. 48-63, spring 2006.

POOLEY, C.; TURNBULL, J.; ADAMS, M. A mobile century? Hampshire: Ashgate Publishing Limited, 2005.

RASMUSSEN, K. Børnene i kvarteret - kvarteret i børnene. [The children in the neighborhood - the neighborhood in the children]. Frederiksberg: Roskilde Universitetsforlag, Denmark, 2004. 
RASMUSSEN, K.; SMIDT, S. Children in the neighbourhood: the neighbourhood in the children. In: CHRISTENSEN, P.; O'BRIEN, M. (Eds.). Children in the city. London/ New York: Routledge Falmer, 2003. p. 82-100.

SMITH, F.; BARKER, J. Contested spaces: Children's experiences of out of school care in England and Wales. Childhood, Norway, v. 7, n. 3, p. 315-333, aug. 2000.

VALENTINE, G. "Oh yes I can". "Oh no you can't": Children and parents' understanding of kids' competence to negotiate public space safely. Antipode, London, v. 29, n. 1, p. 65-89, dec. 1997.

WORLD HEALTH ORGANIZATION (WHO). Promoting Active Living in and through Schools - Policy Statement and Guidelines for Action - report of a WHO meeting, Esbjerg, Denmark, 25-27. May 1998.

YATES, F. A. The Art of Memory. Chicago: University of Chicago Press, 1966.

Recebido em 29 de abril de 2014.

Aprovado em 24 de outubro de 2014.

\section{Errata}

No artigo Mobilidades cotidianas das crianças: combinando etnografia, GPS e tecnologias de telefone móvel em pesquisa publicada no número 128, volume 35, da Revista Educação \& Sociedade, na página 699, onde se lia:

Pia Hartrup Christensen; Miguel Romero Mikkelsen; Thomas Alexander Sick Nielsen; Henrik Harder

\section{Leia-se:}

Pia Haudrup Christensen; Miguel Romero Mikkelsen; Thomas Alexander Sick Nielsen; Henrik Harder 